\title{
Temporal changes in settlement, lipid content and lipid composition of larvae of the spawning hermatypic coral Acropora tenuis
}

\author{
Saki Harii ${ }^{1{ }^{4}, *}$, Kazuo Nadaoka $^{1}$, Masanobu Yamamoto ${ }^{2}$, Kenji Iwao $^{3}$ \\ ${ }^{1}$ Department of Mechanical and Environmental Informatics, Graduate School of Information Science and Engineering, \\ Tokyo Institute of Technology, 2-12-1 Ookayama, Meguro-ku, Tokyo 152-8552, Japan \\ ${ }^{2}$ Faculty of Environmental Earth Science, Hokkaido University, Kita-10, Nishi-5, Kita-ku, Sapporo 060-0810, Japan \\ ${ }^{3}$ Akajima Marine Science Laboratory, 179 Aka, Zamami son, Okinawa 901-3311, Japan \\ ${ }^{4}$ Present address: Graduate School of Engineering and Science, University of the Ryukyus, Nishihara, Okinawa 903-0213, Japan
}

\begin{abstract}
Stored lipids in marine planktonic larvae play an important role in buoyancy and as an energy source and thus are a key to understanding the dispersal and settlement potential of larvae. However, little is known about lipid content and composition in different coral species or their temporal changes during larval dispersal. We examined the lipid content and composition of eggs and planula larvae of Acropora tenuis, a reef-building coral, and their temporal changes over the course of larval dispersal and settlement. The total content and composition of lipids in newly released planulae of the brooding corals A. brueggemanni, Pocillopora damicornis and Heliopora coerulea were also examined for comparison. A. tenuis eggs were positively buoyant; lipids accounted for $85 \%$ of their dry weight, but decreased to $50 \%$ of their dry weight within $30 \mathrm{~d}$ after spawning. Wax esters were a major component of lipids in the eggs; they decreased appreciably by $5 \mathrm{~d}$ after spawning and decreased thereafter. In contrast, the phospholipid content remained almost constant. The period of rapid decrease in wax esters occurred before settlement, suggesting that $A$. tenuis planulae consume mainly wax ester lipids as an energy source during the planktonic phase. In contrast, the lipid content of $H$. coerulea planulae, which have a shorter dispersal period, was lower (41\% of dry weight) than that found in 5-d-old planulae of $A$. tenuis and newly released planulae of $A$. brueggemanni and $P$. damicornis (>58\% of dry weight). Triacylglycerols in lipids were detected in $P$. damicornis and $H$. coerulea planulae, which settle quickly after release, but not in $A$. tenuis or $A$. brueggemanni, suggesting that triacylglycerols are used for rapid energy. These findings suggest that lipids are used for buoyancy and as an energy source and are related to differences in the dispersal period of planulae among coral species.
\end{abstract}

KEY WORDS: Corals · Dispersal $\cdot$ Larvae $\cdot$ Lipid composition $\cdot$ Lipid content $\cdot$ Settlement Resale or republication not permitted without written consent of the publisher

\section{INTRODUCTION}

Larval dispersal and recruitment in marine invertebrates play a significant role in the maintenance of adult populations (Underwood \& Keough 2001). Larval dispersal is determined physically by ocean currents and biologically by egg and larval behaviour, buoyancy in the water column (Morgan 1995, Young 1995) and the period during which larvae can settle after spawning or release (settlement period). The buoyancy of marine invertebrate eggs and larvae is affected by their lipid content (Chia et al. 1984). For example, lipid-rich sea urchin eggs (Emlet \& Hoegh-Guldberg 1997) and eggs of several broadcast-spawning corals with high lipid content (Arai et al. 1993, Wellington \& Fitt 2003) are positively buoyant, whereas lipid-lean planulae of Heliopora coerulea are benthic (Harii et al. 2002). 
The settlement period, in contrast, is constrained by the energy sources of larvae. Marine invertebrate larvae can be divided into species that obtain energy to develop and metamorphose by feeding on plankton (planktotrophic) and those that rely mainly on stored nutrients (lecithotrophic; Thorson 1950). The major energy sources for both experimentally unfed planktotrophic and lecithotrophic larvae during their development include lipids and proteins (e.g. Vavra \& Manahan 1999, Marsh et al. 2001, Moran \& Manahan 2003, 2004, Sewell 2005) and dissolved organic material (DOM) from seawater (e.g. Jaeckle \& Manahan 1989, Shilling et al. 1996, Ben-David-Zaslow \& Benayahu 2000). Among these, lipids are considered to be the most plausible energy source in coral planula larvae (Richmond 1987).

The settlement periods of some brooding coral planulae have been examined in relation to their lipid content. Planulae of the coral Pocillopora damicornis have a high lipid content (70\% of dry weight) and consume lipids during the planktonic phase, suggesting that it may be a sufficient energy source during long settlement periods (Richmond 1987). In contrast, planulae of the blue coral Heliopora coerulea have a lower lipid content $(54 \%$ of dry weight) and have a shorter larval settlement period than those of P. damicornis (Harii et al. 2002), highlighting the importance of lipids in determining larval dispersal periods. These correlative studies between lipid content and settlement period have focused on brooding corals that release planulae larvae. On the other hand, temporal changes in the lipid content of larvae from spawning corals have not been examined, although maximum settlement periods have been reported (>78 d after spawning; Wilson \& Harrison 1998, Nishikawa et al. 2003, Nozawa \& Harrison 2005). Given that the majority of coral species spawn, rather than brood (Harrison \& Wallace 1990), this is an important aspect in understanding the distribution of adult corals and the conservation of reefs.

The lipid composition is also important for buoyancy and as an energy source in marine organisms. Triacylglycerols, a component of lipids, are a primary energy source during larval development in marine invertebrates (Moran \& Manahan 2003, 2004, Sewell 2005). Wax esters are considered to govern buoyancy and act as an energy source (Nevenzel 1970, Lee et al. 1971, Villinski et al. 2002). The lipid content of coral eggs has a high proportion of wax esters that may contribute substantially to positive buoyancy (Arai et al. 1993). Although wax esters in coral planulae may also act as an energy source during the planktonic phase, temporal changes in lipid composition have not been examined.
Therefore, we examined temporal changes in the larval settlement rates, lipid content and lipid composition of eggs and planulae of the spawning coral Acropora tenuis to evaluate the use of lipids during the planktonic phase. A. tenuis is a common coral on upper reef slopes in the western Pacific and Red Sea (Veron 2000). In addition, the initial lipid content and composition were compared with those of the planulae of the brooding corals A. brueggemanni, Pocillopora damicornis and Heliopora coerulea.

\section{MATERIALS AND METHODS}

Collection of larvae. About 10 branches of Acropora tenuis were collected during the day from 10 colonies at Akajima (Aka Island), Okinawa, Japan, prior to spawning in May 2002, and were maintained in separate containers under laboratory conditions. All branches spawned on 29 May 2002. After spawning, sperm and egg bundles from all colonies were mixed and gathered into 1001 containers for fertilisation. The fertilised eggs were washed twice in filtered seawater (FSW) and kept in the containers. After $1.5 \mathrm{~d}$, planulae were moved to 21 plastic containers (hereafter 'large container') in preparation for settlement experiments and lipid analysis. The containers were filled with FSW and kept under $12 \mathrm{~h}$ light: $12 \mathrm{~h}$ dark conditions in an incubator at $26^{\circ} \mathrm{C}$. All planulae were transferred to new large containers filled with fresh FSW daily. The planulae remained in planktonic phase and did not usually settle on the container in the absence of settlement substrata.

For the other species, 5 colonies of Pocillopora damicornis, 10 colonies of Acropora brueggemanni, and 20 female branches from 20 colonies of Heliopora coerulea were collected on Ishigaki Island, Okinawa, in July 2004. The colonies of each species were maintained in large tanks at $29^{\circ} \mathrm{C}$ with running seawater in a laboratory until planulae were released. The planulae, collected at least once a day during their release periods, were kept in new large containers filled with FSW for settlement experiments or lipid analysis.

Larval settlement. Fifty planulae were transferred from the large container to each of 5 small plastic containers containing $0.4 \mathrm{l}$ of FSW and 1 settlement plate ( $5 \times 5 \mathrm{~cm}$ and $0.5 \mathrm{~cm}$ thick unglazed bathroom tile) . The plates had been submerged on a reef for 3 mo prior to the experiment to create natural biological conditions on their surfaces. The lower surface of the plate was held $5 \mathrm{~mm}$ above the floor of the container by a stainless steel nut. This experimental procedure was performed on the third to seventh consecutive days after spawning, and then on Days 10, 15, 20 and 30. 
Only 3 containers were used on Day 30. For each experiment, the planulae were maintained at $26^{\circ} \mathrm{C}$ for $24 \mathrm{~h}$ in still FSW. The number of planulae crawling and settling on the plates was counted under a dissecting microscope after $24 \mathrm{~h}$. The term 'crawling planulae' refers to larvae that were moving on the plates. Planulae that had attached and had begun to metamorphose with no possibility of active detachment and further migration were defined as settled.

For brooding corals, 20 and 50 newly released planulae of Acropora brueggemanni and Pocillopora damicornis, respectively, were transferred to each of 3 containers and tested in the same manner as in the above settlement experiment, but only on the first day after release at $29^{\circ} \mathrm{C}$. We did not examine the settlement of Heliopora coerulea planulae.

Lipid analysis. Immediately after spawning, 100 unfertilised Acropora tenuis eggs were collected on pre-combusted GF filters $\left(400^{\circ} \mathrm{C}\right.$ for $\left.4 \mathrm{~h}\right)$. Additionally, 100 A. tenuis planulae were randomly collected from the large containers on filters $2 \mathrm{~d}$ after spawning, and then at the end of the 4,10,20 and $30 \mathrm{~d}$ settlement experiments. Four filters were used on each collection day, except for Day 2 when 5 filters were used. Approximately 50 to 100 planulae of A. brueggemanni, Pocillopora damicornis and Heliopora coerulea were collected on filters immediately after their release; 4, 3 and 3 filters were used, respectively. After collection, the filters were rinsed with distilled water to remove salt and then stored at -10 to $-20^{\circ} \mathrm{C}$ until they were freeze-dried for subsequent lipid analysis.

Lipids were extracted 5 times with 5 min rounds of ultrasonication with $5 \mathrm{ml}$ of dichloromethane: methanol (6:4). The lipid extracts were concentrated and passed through a short bed of $\mathrm{Na}_{2} \mathrm{SO}_{4}$ to remove water and then weighed. The extracted lipids were analyzed using a thin-layer chromatography-flame ionisation detector (TLC-FID; Iatroscan MK-5, Iatron Laboratories); 3 or 4 extracted lipid samples from each collection day were analyzed between 3 and 11 times. Two different solvent systems were used to detect 3 chromatograms $\operatorname{rod}^{-1}$ (modified after Yamamoto et al. 2000). The first chromatogram was obtained after 20 min of development in hexane:diethyl ether (96:4). Lipids were partly detected by TLC-FID analysis. The rods were developed again for $20 \mathrm{~min}$ in hexane:diethyl ether:acetic acid (60:17:0.15), and the remaining lipids were detected. The lipid composition was quantified using FID calibration curves obtained by analyzing the standard compounds palmitic acid palmityl ester for wax esters, 1, 2 dipalmitoyl-3-oleoylrac-glycerol for triacylglycerols and L- $\alpha$-phosphatidylcholine for phospholipids (Sigma).
Statistical analyses. One-way ANOVA was used to test for significant differences in planula settlement rates over time; the container was the experimental unit, the number of planulae for each time period examined was the independent factor and time was treated as a fixed factor. One-way ANOVA was also used to examine differences in the lipid content and composition of Acropora tenuis eggs and planulae over time (treatment: time; experimental unit: the collection filter). Differences in lipid content were examined for 5-d-old $A$. tenuis planulae and newly released planulae of Pocillopora damicornis, A. brueggemanni and Heliopora coerulea using 1-way ANOVA. All percentage data were arcsine transformed prior to analysis because they did not meet the a priori assumption of normality (Underwood 1981). The homogeneity of variances was examined using Bartlett's test. A Tukey post hoc test was used to examine significant differences over time.

\section{RESULTS}

Eggs of Acropora tenuis initially floated on the seawater surface and developed into swimming planula larvae that sometimes swam vertically in the large container within $2 \mathrm{~d}$ after spawning. They became less active over time, and most were found on the floor of the container $20 \mathrm{~d}$ after spawning. They began crawling on the plates $3 \mathrm{~d}$ after spawning, and some individuals settled (Fig. 1). The settlement rate varied significantly over time $\left(F_{8,34}=20.9, \mathrm{p}<0.01\right.$; Fig. 1$)$. The

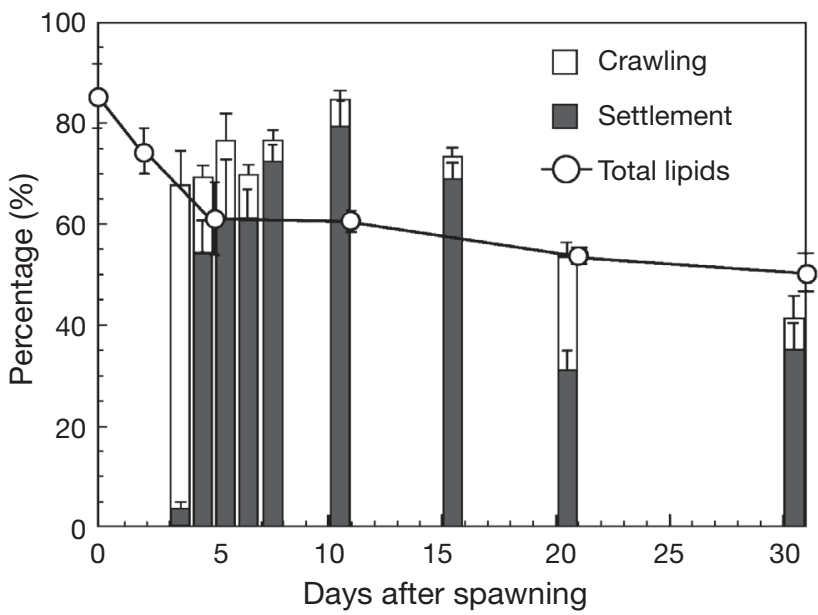

Fig. 1. Acropora tenuis. Stacked column graph of changes in mean percentage of crawling (white bars at top) and settled planulae (grey bars at bottom) in the small container $( \pm \mathrm{SE}$, $\mathrm{n}=5$ except $\mathrm{n}=3$ at $30 \mathrm{~d}$ after spawning) and mean percentage of total lipid of planulae in large containers $( \pm \mathrm{SE}, \mathrm{n}=4$ except $\mathrm{n}=5$ at $2 \mathrm{~d}$ after spawning) over the $31 \mathrm{~d}$ after spawning 
highest settlement rate was $79.6 \pm 4.8 \%(\mathrm{n}=5) 10 \mathrm{~d}$ after spawning, and it was significantly higher than the settlement rates 3,20 and $30 \mathrm{~d}$ after spawning (Tukey test, $\mathrm{p}<0.01$ ). At $30 \mathrm{~d}$ after spawning, $35.3 \pm 5.2 \%$ ( $\mathrm{n}=$ 3 ) of the planulae remained able to settle. For brooding corals, $80.0 \pm 8.7 \%(n=3)$ and $44.7 \pm 7.9 \%(n=3)$ of newly released planulae of Acropora brueggemanni and Pocillopora damicornis, respectively, settled on the plates by $1 \mathrm{~d}$ after release.

The lipid content of Acropora tenuis eggs and planulae differed significantly over time $\left(F_{5,19}=8.05\right.$, $\mathrm{p}<0.01$; Fig. 1). Mean percentage of lipid was $85.2 \pm$ $6.3 \%(\mathrm{n}=4)$ of the total dry weight of eggs and decreased to $50.2 \pm 3.7 \%(\mathrm{n}=4)$ by $31 \mathrm{~d}$ after spawning (Fig. 1). The percentage of lipid in eggs was significantly higher than that in planulae at 5 or more days old (Tukey test, $\mathrm{p}<0.05$ ). Although the percentage of lipid was not significantly different between 5 and $31 \mathrm{~d}$ after spawning, it was $10.6 \%$ lower on Day 31 (Fig. 1). For 5-d-old A. tenuis planula and the other planulae of 3 brooding species, the mean percentages of lipid were significantly different only between newly released planulae of Pocillopora damicornis and Heliopora coerulea (1-way ANOVA, $F_{3,10}=5.34, \mathrm{p}<0.05$; Tukey test, $\mathrm{p}<0.05$; Table 1).

Two groups of lipids, wax esters and phospholipids were detected in eggs or newly released planulae of all examined species. Wax esters were the major lipid component (Fig. 2, Table 1). In addition, triacylglycerols were found in Pocillopora damicornis and Heliopora coerulea planulae, but few or no triacylglycerols were detected in the other corals (Fig. 2, Table 1). The wax ester content of eggs or planulae of Acropora tenuis varied significantly over time $\left(F_{5,12}=5.0, \mathrm{p}<\right.$ 0.01 ; Fig. 3). It decreased from $2.02 \pm 0.29 \mathrm{mg}$ per 100 eggs to $0.63 \pm 0.07 \mathrm{mg}$ per 100 individuals $31 \mathrm{~d}$ after spawning. The wax ester content of eggs differed significantly from that of planulae more than $5 \mathrm{~d}$ old (Tukey test, $\mathrm{p}<0.05$ ). In contrast, the phospholipid content of $A$. tenuis did not change significantly over time $\left(F_{5,12}=3.1, \mathrm{p}>0.05\right.$; Fig. 3$)$.
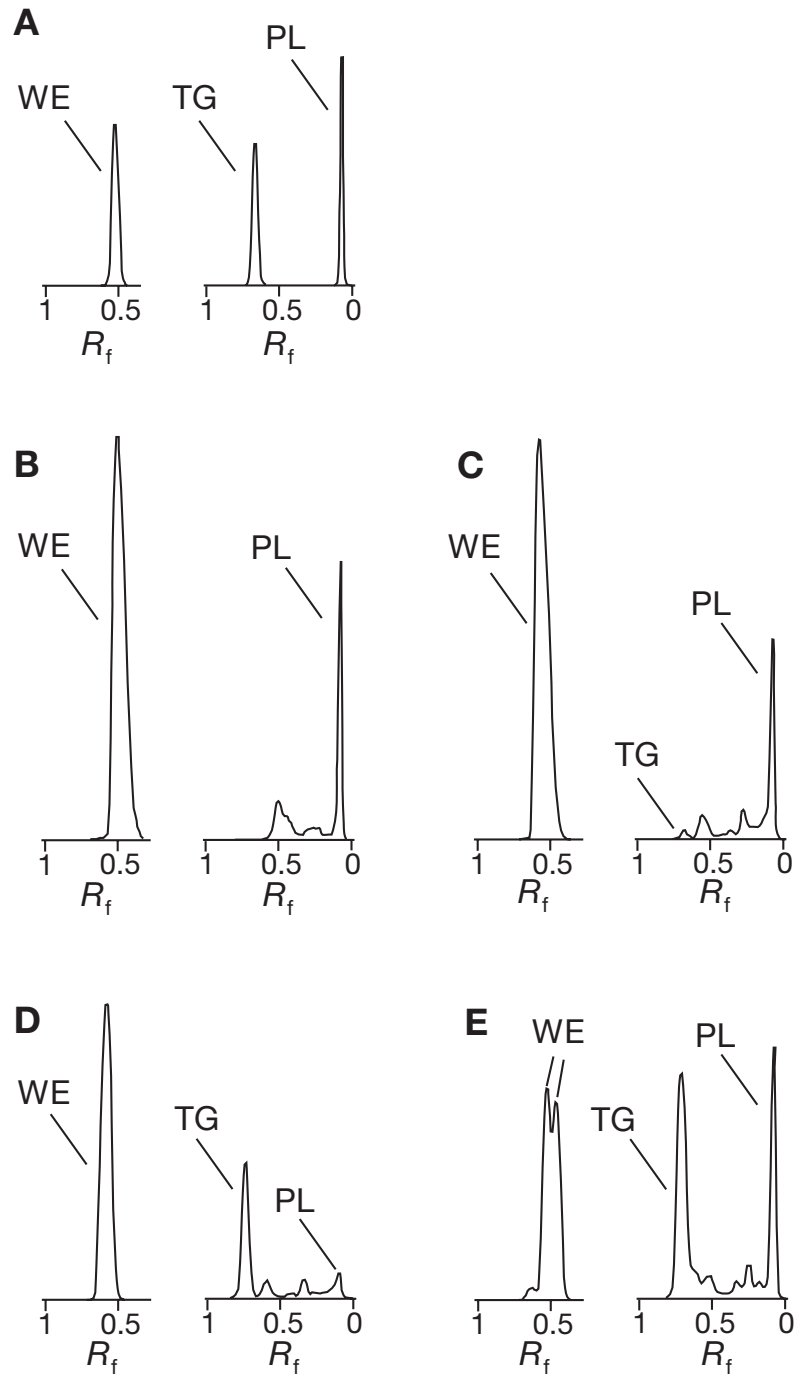

Fig. 2. TLC-FID chromatograms of lipid composition in eggs and planulae of (A) standard components, (B) Acropora tenuis, (C) A. brueggemanni, (D) Pocillopora damicornis and (E) Heliopora coerulea. $R_{\mathrm{f}}$ : rate of flow; WE: wax esters $\left(R_{\mathrm{f}}=\right.$ 0.47 to 0.65$)$; TG: triacylglycerols $\left(R_{\mathrm{f}}=0.57\right.$ to 0.71$)$; PL: phospholipids $\left(R_{\mathrm{f}}=0.01\right.$ to 0.10$)$. For each species, the chromatogram on the left was developed in hexane:diethyl ether [96:4], whereas that on the right was developed in hexane: diethyl ether:acetic acid [60:17:0.15]

Table 1. Acropora tenuis, Acropora brueggemanni, Pocillopora damicornis and Heliopora coerulea. Mean ( \pm SE) percentage of lipid content and composition in eggs and planulae. WE, wax esters; TG, triacylglycerols; PL, phospholipids; numbers in parentheses: sample size

\begin{tabular}{|c|c|c|c|c|c|}
\hline \multirow[t]{2}{*}{ Species } & \multirow[t]{2}{*}{ Larval days } & \multirow{2}{*}{$\begin{array}{c}\text { Total lipids } \\
\text { in dry weight }(\%)\end{array}$} & \multicolumn{3}{|c|}{ Total lipid composition in dry lipids (\%) } \\
\hline & & & WE & TG & PL \\
\hline A. tenuis & 5-d-old planulae & $61.0 \pm 6.9(4)$ & $53.4 \pm 3.2(3)$ & $0.0(3)$ & $22.6 \pm 1.5(3)$ \\
\hline A. brueggemanni & Newly released planulae & $58.0 \pm 1.4(4)$ & $72.4 \pm 5.5(4)$ & $0.4 \pm 0.2(4)$ & $10.9 \pm 1.0(4)$ \\
\hline P. damicornis & Newly released planulae & $68.1 \pm 3.6(3)$ & $60.3 \pm 6.0(3)$ & $16.5 \pm 0.8(3)$ & $3.2 \pm 0.1(3)$ \\
\hline H. coerulea & Newly released planulae & $41.3 \pm 0.1(3)$ & $38.2 \pm 4.2(3)$ & $28.0 \pm 2.2(3)$ & $12.8 \pm 0.2(3)$ \\
\hline
\end{tabular}




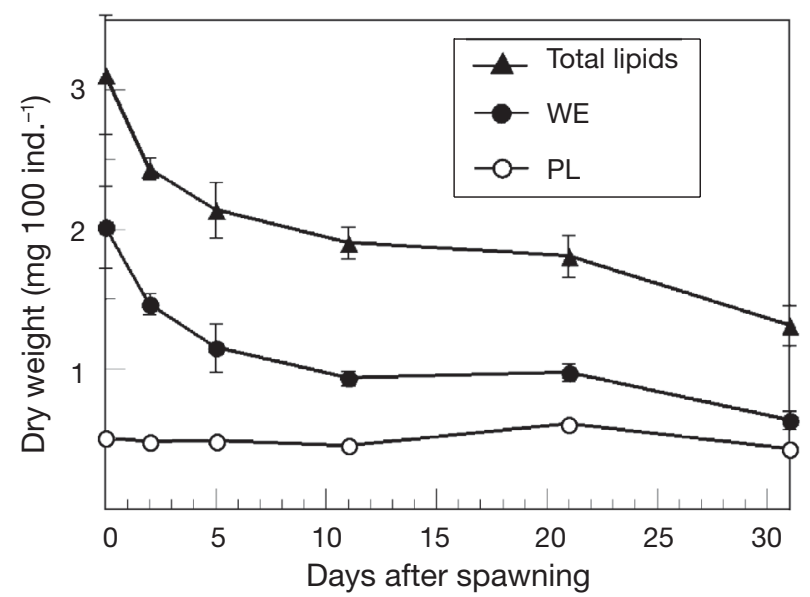

Fig. 3. Acropora tenuis. Temporal changes in the lipid composition of planulae by dry weight $( \pm \mathrm{SE}, \mathrm{n}=3)$ over the $31 \mathrm{~d}$ after spawning. WE: wax esters; PL: phospholipids

\section{DISCUSSION}

\section{Relationship between lipid content and larval settlement period}

Acropora tenuis planulae began swimming vertically $2 \mathrm{~d}$ after spawning and began settling after $3 \mathrm{~d}$. Coral planulae from other spawning species also develop into motile larvae within $3 \mathrm{~d}$ of spawning, subsequently beginning settlement $4 \mathrm{~d}$ after spawning (Babcock \& Heyward 1986). This period from development to initial settlement of $A$. tenuis occurs in concert with a dramatic decrease in total lipid content by $5 \mathrm{~d}$ after spawning, suggesting that lipids are a major energy source during the early stage larval development. More than $50 \%$ of larvae settled 4 to $15 \mathrm{~d}$ after spawning, with low crawling rates. Since the amount of lipids decreased slightly after $5 \mathrm{~d}$, many planulae likely had enough energy to settle after crawling in this period. On the other hand, the settlement rate decreased 20 to $30 \mathrm{~d}$ after spawning. The crawling rates increased $20 \mathrm{~d}$ after spawning and decreased again $30 \mathrm{~d}$ after spawning. Some planulae may have lost the energy for settlement by Day 20, but still retain energy for crawling. By Day 30 they may have depleted the energy required for both crawling and settlement.

Variation in the initial amount of lipids available in planulae among different coral species was related to the variation in the larval settlement periods. Eggs and 5-d-old planulae of Acropora tenuis have $>60 \%$ lipids in their bodies. These planulae could settle even $30 \mathrm{~d}$ after spawning. Planulae of several acroporid corals maintain a settlement ability $30 \mathrm{~d}$ after spawning (Morse et al. 1996), and A. tenuis planulae retain their settlement ability even 69 d after spawning (Nishikawa et al. 2003). A. tenuis planulae may have a longer larval settlement period than those of lipid-lean corals, giving them the potential to disperse over a wider area. The higher gene flow among populations of $A$. tenuis than among populations of the brooding coral Stylophora pistillata confirms that $A$. tenuis has a higher dispersal potential than $S$. pistillata (Nishikawa et al. 2003).

A correlation between lipid content and settlement period also occurs among species of brooding corals. Lipid-rich planulae of Pocillopora damicornis have long larval settlement periods (>100 d; Richmond 1987, Harii et al. 2002). Richmond (1987) assumed that this was due to the lipid energy stores and also because the larvae could obtain photosynthetic energy from maternally inherited zooxanthellae that were present on release. These traits account for the wide distribution of $P$. damicornis in the Indo-Pacific region. In contrast, the lipid content of Heliopora coerulea planulae was only $41.3 \%$ of their dry weight. Most of them settle soon after release; however, their settlement rate decreases to only $3 \%$ at $20 \mathrm{~d}$ after release (Harii et al. 2002). They mainly disperse and settle close to adult colonies in natal reefs, which may correspond to the limited adult distribution (Harii \& Kayanne 2003). Also, newly released, lipid-lean planulae of the soft coral Heteroxenia fuscescens (lipids comprise $51.5 \%$ of the dry weight; Ben-David-Zaslow \& Benayahu 2000) have a shorter larval settlement period than those of $P$. damicornis (49 d; Ben-David-Zaslow \& Benayahu 1996). Lipid-lean larvae may settle quickly to maintain local populations at the expense of long-distance dispersal.

Lipids are a major source of endogenous energy of other marine larvae, including shrimp (Nates \& McKenney 2000), abalone (Moran \& Manahan 2003), sea stars (Bryan 2004) and sea urchins (Sewell 2005). For example, Haliotis fulgens larvae used $50 \%$ of their lipids in development from egg to metamorphic competence (8 di Moran \& Manahan 2003). These larvae require lipids during the planktonic phase as a primary energy source, which is consistent with our findings from coral larvae. The differing amounts of lipids among the coral planula species studied may influence larval settlement periods, which, in turn, may affect adult populations and distributions.

\section{Lipid composition and their different utilisation in coral planulae}

In all the corals examined, we found higher percentages of wax esters than phospholipids in the lipid fractions; this is in agreement with the findings of Arai et al. (1993). However, the lipid composition varied 
among species. Planulae of Acropora tenuis and A. brueggemanni contained mainly wax esters with similar chromatographic patterns, whereas Pocillopora damicornis and Heliopora coerulea planulae contained both wax esters and triacylglycerols. A. tenuis and $A$. brueggemanni planulae contained few or no triacylglycerols. The pattern of lipid composition among coral planulae may be similar among closely related species such as the acroporid species examined. The biochemical composition and metabolic rate of larvae are similar among species in the abalone genus Haliotis (Moran \& Manahan 2003). We have not examined the metabolism of coral planulae; however, species of the same genus and with similar lipid compositions may have similar metabolic patterns.

Wax esters and triacylglycerols are considered possible energy sources for marine organisms (Nevenzel 1970, Lee et al. 1971, 2006, Villinski et al. 2002). Wax esters are regulated by wax ester lipases, allowing for their slower rate of use, whereas triacylglycerols can be quickly hydrolysed to provide energy for short-term needs (Lee et al. 2006). The wax ester content of Acropora tenuis planulae decreased gradually after they developed into planula larvae. The planulae may slowly consume wax esters during the planktonic phase. Pocillopora damicornis and Heliopora coerulea larvae contain triacylglycerols, as well as wax esters. Because these larvae can settle quickly after release (Harii et al. 2002), they may require triacylglycerols as a rapid energy source. In addition, because planulae of $P$. damicornis have more wax esters than those of $H$. coerulea, they may also use wax esters for long-term energy. The relative importance of wax esters and triacylglycerols as energy sources may vary among species of coral planulae.

Differential use of wax esters and triacylglycerols occurs in other marine organisms (Lee et al. 1971, Hunter et al. 1998, Moran \& Manahan 2003). The copepod Gaussia princes slowly consumes wax esters after triacylglycerols are exhausted under starvation conditions (Lee et al. 1971). The eggs of planktotrophic species are dominated by triacylglycerols, whereas the eggs of lecithotrophic species are dominated by wax esters, suggesting that wax esters play a role in postmetamorphic provisioning of eggs in echinoids and asteroids (Villinski et al. 2002). Larval settlement of the bryozoan Bugula neritina is reduced $24 \mathrm{~h}$ after larval release because triacylglycerols are consumed during the initial $24 \mathrm{~h}$ (Hunter et al. 1998). Triacylglycerols dominate in larvae of the abalone Haliotis fulgens and $H$. sorenseni and decrease during development because they are the primary energy source (Moran \& Manahan 2003). Larval settlement periods of Haliotis larvae are only about $19 \mathrm{~d}$ (Takami et al. 2002). Planktonic periods may be partly controlled by the amount of nutritional reserves in Haliotis. We suggest that wax-ester-rich larvae may be more adapted to longdistance dispersal, whereas larvae with triacylglycerols may settle quickly and have shorter planktonic periods.

Wax esters also play an important role in buoyancy in marine organisms (Nevenzel 1970, Lee et al. 1971, Villinski et al. 2002). Positively buoyant Acropora tenuis eggs had a high wax ester content. Spawning corals such as acroporids release bundles containing mainly several eggs and sperm sacs; the bundles break up on the water surface and fertilisation occurs (Harrison \& Wallace 1990). The high proportion of wax esters in A. tenuis eggs may keep the eggs near the sea surface and hence increase the opportunity for fertilisation. Because fertilised eggs float on the surface, they disperse beyond the natal reefs by various currents like ocean, tidal and wind-driven currents (Willis \& Oliver 1990), which may allow dispersal over a vast area. In contrast, newly released Heliopora coerulea larvae had the lowest wax ester content. These larvae are benthic, do not actively swim (Harii et al. 2002) and are distributed in the middle or bottom of the water column near the adult populations in the field (Harii \& Kayanne 2003). Wax esters also control buoyancy in other groups of marine invertebrate larvae. Several species of echinoids and asteroids have positively buoyant eggs that contain a high proportion of wax esters (Villinski et al. 2002), whereas Haliotis abalone have eggs that contain mainly triacylglycerols (Moran \& Manahan 2003) and are generally negatively or neutrally buoyant (Ino 1952, McShane 1995). Eggs or less active larvae may regulate their positions in the water column by changing the proportions of wax esters and triacylglycerols that they contain, thereby determining the dispersal direction by placing them in different oceanic currents.

Phospholipids control structural function and cell membrane formation in marine organisms (Lee et al. 1971, 2006). The phospholipid content of Acropora tenuis planulae was almost constant during the planktonic phase. These planulae may retain phospholipids for the formation of new cell membranes during development and after settlement and metamorphosis. This pattern of phospholipid content is consistent with changes in lipid compositions in other marine organisms in which the phospholipid fraction changes little during development (Nates \& McKenney 2000, Kattner et al. 2003, Moran \& Manahan 2003, 2004).

This study suggests that lipids, especially wax esters, in Acropora tenuis planulae are both a controlling factor of positive buoyancy and a long-term energy source. Thus, lipids are likely to affect fertilisation success and the settlement period. In contrast, the larvae of Pocillopora damicornis and Heliopora coerulea have 
triacylglycerols for short-term utilisation; thus, these planulae can settle close to the parent population soon after release. In addition, $A$. tenuis planulae retain more lipids (>50\% $30 \mathrm{~d}$ after spawning) than generally contained in adult corals (9 to $47 \%$; Harland et al. 1993, Yamashiro et al. 1999). Although lipid use after settlement has not been investigated, the planulae are likely to retain lipids, especially wax esters and phospholipids, for both metamorphosis and post-metamorphosis prior to settlement. Coral planulae may have different dispersal patterns that are determined by species-specific differences in the amount, composition and use of lipids.

Acknowledgements. We thank M. Omori, Akajima Marine Science Laboratory, for discussions and comments on the manuscript. We are grateful to H. Kubo and K. Iwai, Yaeyama Branch Station of the Okinawa Prefectural Fisheries Experiment Station, for their valuable input. E. Shimabukuro and M. Taira assisted with the fieldwork. We also thank W. K. W. Loh and M. Rodriguez-Lanetty, The University of Queensland, R. van Woesik, Florida Institute of Technology, H. Kayanne, University of Tokyo, and 4 anonymous reviewers for their comments. This research was financially supported by a Ministry of Education, Culture, Sports, Science and Technology Grant-in-Aid for Young Scientists (B) No. 14740416, and by Japan Society for the Promotion of Science Grants-in-Aid for Scientific Research (B) No. 12450198 and (A) No. 14205071.

\section{LITERATURE CITED}

Arai T, Kato M, Heyward A, Ikeda Y, lizuka T, Murayama T (1993) Lipid composition of positively buoyant eggs of reef-building corals. Coral Reefs 12:71-75

Babcock RC, Heyward AJ (1986) Larval development of certain gamete-spawning scleractinian corals. Coral Reefs 5: 111-116

Ben-David-Zaslow R, Benayahu Y (1996) Longevity, competence and energetic content in planulae of the soft coral Heteroxenia fuscescens. J Exp Mar Biol Ecol 206:55-68

Ben-David-Zaslow R, Benayahu Y (2000) Biochemical composition, metabolism, and amino acid transport in planulalarvae of the soft coral Heteroxenia fuscescens. J Exp Zool 287:401-412

Bryan PJ (2004) Energetic cost of development through metamorphosis for the seastar Mediaster aequalis (Stimpson). Mar Biol 145:293-302

Chia FS, Buckland-Nicks J, Young CM (1984) Locomotion of marine invertebrate larvae: a review. Can J Zool 62: 1205-1222

Emlet RB, Hoegh-Guldberg O (1997) Effects of egg size on postlarval performance: experimental evidence from a sea urchin. Evolution 51:141-152

Harii S, Kayanne H (2003) Recruitment and adult distribution of brooding blue coral, Heliopora coerulea, at Ishigaki Island, southwest of Japan. Coral Reefs 22:188-196

Harii S, Kayanne H, Takigawa H, Hayashibara T, Yamamoto M (2002) Larval survivorship, competency periods and settlement of two brooding corals, Heliopora coerulea and Pocillopora damicornis. Mar Biol 141:39-46

Harland AD, Navarro JC, Spencer DP, Fixter LM (1993) Lipids of some Caribbean and Red Sea corals: total lipid, wax esters, triacylglycerols and fatty acids. Mar Biol 117:113-117
Harrison PL, Wallace CC (1990) Reproduction, dispersal and recruitment of scleractinian corals. In: Dubinsky Z (ed) Ecosystems of the world, 25. Elsevier Science, Amsterdam, p 133-207

Hunter E, Okano K, Tomono Y, Fusetani N (1998) Functional partitioning of energy reserves by larvae of the marine bryozoan Bugula neritina (L.). J Exp Biol 201: $2857-2865$

Ino $T$ (1952) Biological studies of the propagation of the Japanese abalone (genus Haliotis). Bull Tokyo Reg Fish Res Lab 5:29-102

Jaeckel WB, Manahan DT (1989) Feeding by a 'nonfeeding' larva: uptake of dissolved amino acids from seawater by lecithotrophic larvae of the gastropod Haliotis rufescens. Mar Biol 103:87-94

Kattner G, Graeve M, Calcagno JA, Lovrich GA, Thatje S, Anger K (2003) Lipid, fatty acid and protein utilization during lecithotrophic larval development of Lithodes scantolla (Molina) and Paralomis granulose (Jacquinot). J Exp Mar Biol Ecol 292:61-74

Lee RF, Hirota J, Barnett AM (1971) Distribution and importance of wax esters in marine copepods and other zooplankton. Deep-Sea Res 18:1147-1165

Lee RF, Hagen W, Kattner G (2006) Lipid storage in marine zooplankton. Mar Ecol Prog Ser 307:273-306

Marsh AG, Mullineaux L, Young C, Manahan D (2001) Larval dispersal potential of the tubeworm Riftia pachyptilia at deep-sea hydrothermal vents. Nature 411:77-80

McShane PE (1995) Recruitment variation in abalone: its importance to fisheries management. Mar Freshw Res 46: $555-570$

Moran AL, Manahan DT (2003) Energy metabolism during larval development of green and white abalone, Haliotis fulgens and $H$. sorenseni. Biol Bull (Woods Hole) 204: 270-277

Moran AL, Manahan DT (2004) Physiological recovery from prolonged 'starvation' in larvae of the Pacific oyster Crassostrea gigas. J Exp Mar Biol Ecol 306:17-36

Morgan SG (1995) The timing of larval release. In: McEdward L (ed) Ecology of marine invertebrate larvae. CRC Press, Boca Raton, FL, p 249-278

Morse ANC, Iwao K, Baba M, Shimoike K, Hayashibara T, Omori M (1996) An ancient chemosensory mechanism brings new life to coral reefs. Biol Bull (Woods Hole) 191: 149-154

Nates SF, McKenney CL (2000) Ontogenetic changes in biochemical composition during larval and early postlarval development of Lepidophthalmus louisianensis, a ghost shrimp with abbreviated development. Comp Biochem Physiol B 127:459-468

Nevenzel JC (1970) Occurrence, function and biosynthesis of wax esters in marine organisms. Lipids 5(3):308-319

Nishikawa A, Katoh M, Sakai K (2003) Larval settlement rates and gene flow of broadcast-spawning (Acropora tenuis) and planula-brooding (Stylophora pistillata) corals. Mar Ecol Prog Ser 256:87-97

Nozawa Y, Harrison PL (2005) Temporal settlement patterns of larvae of the broadcast spawning reef coral Favites chinensis and the broadcast spawning and brooding reef coral Goniastrea aspera from Okinawa, Japan. Coral Reefs 24:274-282

Richmond RH (1987) Energetics, competency, and long-distance dispersal of planula larvae of the coral Pocillopora damicornis. Mar Biol 93:527-533

Sewell MA (2005) Utilization of lipids during early development of the sea urchin Evechinus chloroticus. Mar Ecol Prog Ser 304:133-142 
Shilling FM, Hoegh-Guldberg O, Manahan DT (1996) Source of energy for increased metabolic demand during metamorphosis of the abalone Haliotis refescens (Mollusca). Biol Bull (Woods Hole) 191:402-412

Takami H, Kawamura T, Yamashita Y (2002) Effects of delayed metamorphosis on larval competence, and postlarval survival and growth of abalone Haliotis discus hannai. Aquaculture 213:311-322

Thorson G (1950) Reproductive and larval ecology of marine bottom invertebrates. Biol Rev 25:1-45

Underwood AJ (1981) Technique of analysis of variance in experimental marine biology and ecology. Oceanogr Mar Biol Annu Rev 19:513-605

Underwood AJ, Keough MJ (2001) Supply-side ecology: the nature and consequences of variations in recruitment of intertidal organisms. In: Bertness MD, Gains SD, Hay ME (eds) Marine community ecology. Sinauer Associates, Sunderland, MA, p 183-200

Vavra J, Manahan DT (1999) Protein metabolism in lecithotrophic larvae (Gastropoda: Haliotis rufescens). Biol Bull (Woods Hole) 196:177-186

Veron JEN (2000) Corals of the world, 1. Australian Institute of Marine Science, Townsville, p 360-361

Editorial responsibility: Otto Kinne (Editor-in-Chief), Oldendorf/Luhe, Germany
Villinski JT, Villinski JC, Byrne M, Raff RA (2002) Convergent maternal provisioning and life-history evolution in echinoderms. Evolution 56:1764-1775

Wellington GM, Fitt WK (2003) Influence of UV radiation on the survival of larvae from broadcast-spawning reef corals. Mar Biol 143:1185-1192

Willis BL, Oliver JK (1990) Direct tracking of coral larvae: implications for dispersal studies of planktonic larvae in topographically complex environments. Ophelia 32:145-162

Wilson JR, Harrison PL (1998) Settlement-competency periods of larvae of three species of scleractinian corals. Mar Biol 131:339-345

Yamamoto M, Shiraiwa Y, Inouye I (2000) Physiological responses of lipids in Emiliania huxleyi and Gephyrocapsa oceanica (Haptophyceae) to growth status and their implications for alkenone paleothermometry. Org Geochem 31: 799-811

Yamashiro H, Oku H, Higa H, Chinen I, Sakai K (1999) Composition of lipids, fatty acids and sterols in Okinawan corals. Comp Biochem Physiol B 122:397-407

Young CM (1995) Behavior and locomotion during the dispersal phase of larval life. In: McEdward L (ed) Ecology of marine invertebrate larvae. CRC Press, Boca Raton, FL, p 249-278

Submitted: July 27, 2005; Accepted: June 20, 2006

Proofs received from author(s): September 10, 2007 